\title{
A Comparison of Experimental and Estimated Data Analyses of Solar Radiation, in Adiyaman, Turkey
}

\author{
Haci Sogukpinar *+, Ismail Bozkurt**, Nazif Calis *** \\ *Department of Energy Systems Engineering, Faculty of Technology, University of Adiyaman, Adiyaman 02040, Turkey \\ **Department of Mechanical Engineering, Faculty of Engineering, University of Adiyaman, Adiyaman 02040, Turkey \\ ***Department of Management, Faculty of Economics and Administrative Sciences, University of Adiyaman, Adiyaman \\ 02040, Turkey
}

(hsogukpinar@adiyaman.edu.tr, ibozkurt@adiyaman.edu.tr, ncalis@adiyaman.edu.tr)

\begin{abstract}
${ }^{\ddagger}$ Corresponding Author; First Author, Department of Energy Systems Engineering, Faculty of Technology, University of Adiyaman, Adiyaman 02040, Turkey, Tel: +90 41622338 00/2840, hsogukpinar@adiyaman.edu.tr
\end{abstract}

Received: 25.08.2015 Accepted:17.09.2015

\begin{abstract}
The world's main energy source is the sun. Other energy sources are caused directly or indirectly from the sun. Turkey has a rich potential in terms of solar energy and interest in solar power systems is increasing in the rapidly evolving technology. In all of the solar energy studies needs solar radiation data but solar radiation measurements are not possible on each area. Therefore, estimation of the solar radiation by using a variety of methods is emerging importance. In this study, Turkey and Adiyaman solar energy potential is investigated and statistical analysis was performed for Adiyaman. Various parameters were estimated by using actual solar radiation data from the Meteorology and experimental data were compared with theoretical ones. According to the results of the statistical analyzes, Adiyaman data indicate the best fit with the cubic model.
\end{abstract}

Keywords: Adiyaman sunshine duration, Turkey solar map, Global solar radiation, Angström-Prescott model

\section{Introduction}

Increasing energy demand, shortage of fossil fuels and environmental concerns gives impetus to the development of renewable and sustainable energy sources such as solar, geothermal and wind power. [1]. Turkey has rich reserves of renewable and sustainable energy. Among the renewable energy resources in Turkey, one of the most significant one is the solar power [2]. Turkey's average annual solar radiation is $1311 \mathrm{kWh} / \mathrm{m}^{2}$-year, and has 2640 hours of sunshine duration. In all studies related with solar energy systems are needed to solar radiation data and solar radiation measurement is not possible in everywhere. Therefore, the solar radiation must be predicted by using a variety of methods. Complete and accurate solar radiation data for a particular region is inevitable. For a place the measured values are not available, various models have been improved to estimate solar radiation. In the literature, there are various experimental methods used to predict the global solar radiation [3]. Yorukoglu and Celik [4] used five different models to estimate global solar radiation by using sunshine duration. Daut et. al. [5] suggested a new method which is combination of linear regression and Hargreaves method to estimate the solar radiation. Prieto et. al. [6] improved the correlation between monthly average radiation data and air temperature corresponding to the same temporal sequence of measurements. Papakostas et. al. [7] studied to forecast ambient dry bulb temperature bin-data, based on only the monthly mean temperatures and the solar clearness indicator. Almorox et. al. [8] proposed a new experimental model to intercourse the global solar radiation $(\mathrm{H})$ with its theoretical possible maximum value (Ho), through daily maximum and minimum air temperature.

In this study, statistical analysis was conducted using 6year Adiyaman solar data. Models such as the linear, quadratic, cubic, logarithmic and exponential are used for this purpose. According to the statistical results, Adiyaman data showed the best fit with cubic model. However, quadratic, logarithmic and exponential model shows best fit after cubic model. By using estimated parameters, solar 
radiation values can be estimated for other region. According to the analysis Adiyaman is one of the leading cities in terms of radiation and sunshine duration.

\section{Solar energy potential}

Turkey is a very rich country in terms of solar energy. Turkey's solar map is given in Figure 1. According to Figure 1 , especially in the southern and south eastern part of Turkey is very rich in solar radiation. The highest solar radiation potential from 1800 to $2000 \mathrm{kWh} / \mathrm{m}^{2}$-year comprises in the south-east and south-western areas.

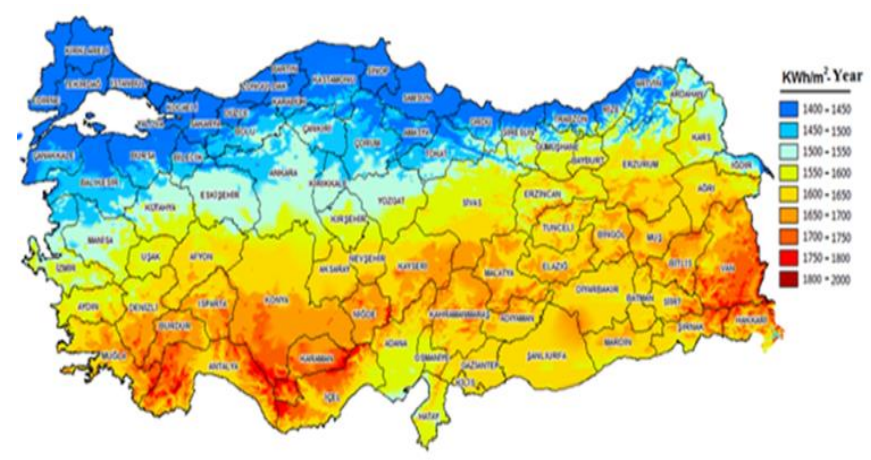

Fig. 1. Turkey’s solar map [9]

Adiyaman, as located west of the Southeastern Anatolia, is one of the provinces where solar energy potential is highest in Turkey. Adiyaman solar map is given in Figure 2. According to Figure 2 solar energy potential ranged from 1600 to $1750 \mathrm{kWh} / \mathrm{m}^{2}$-year in Adiyaman.

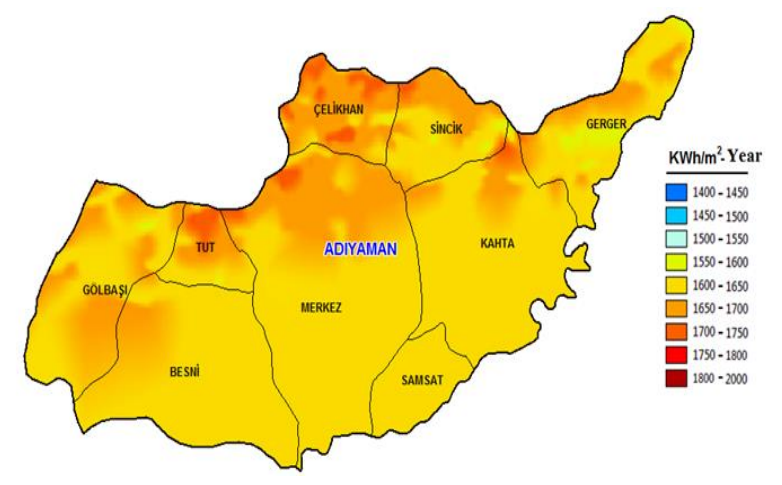

Fig. 2. Adiyaman's solar map [9]

Measurements of the solar radiation and sunshine duration were made in central part of Adiyaman $\left(38^{\circ} 17^{\prime} \mathrm{E}\right.$, $\left.37^{\circ} 46^{\prime} \mathrm{N}\right)$ in between 2005 to 2010 by Meteorological Office [10]. Figure 3 shows Adiyaman solar radiation measurements for six year. As shown in Figure 3, monthly average solar radiation shows little change according to the measurement years. However, general distribution is carried out in a similar manner. Considering the annual average for six year, lowest average with the value of $1.90 \mathrm{kWh} / \mathrm{m}^{2}$-day takes placed in December and highest value is in June with $7.00 \mathrm{kWh} / \mathrm{m}^{2}$-day.

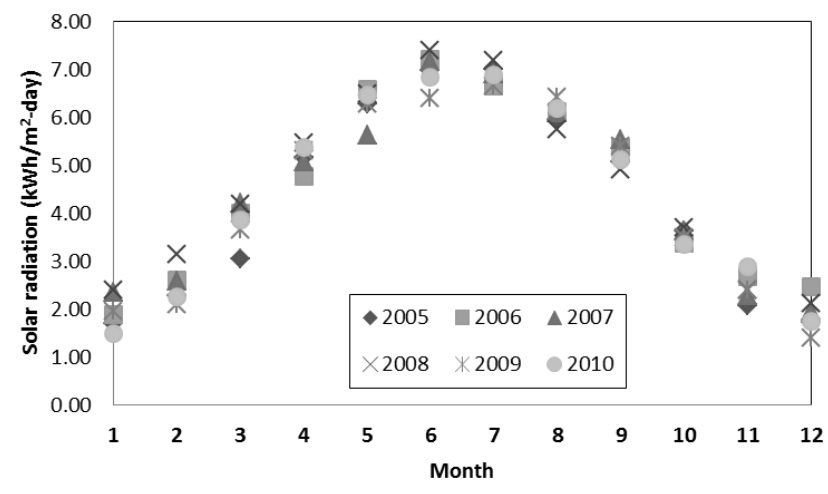

Fig. 3. Adiyaman's solar radiation data from 2005 to 2010

Adiyaman sunshine duration in between 2005 to 2010 was shown in Figure 4. As shown in figure, maximum daily average sunshine duration by month was achieved in July with value of $12.28 \mathrm{~h}$ /day and lowest in January with 3.70 $\mathrm{h} /$ day. Adiyaman is one of the province in Turkey with having the highest average sunshine duration $(10 \mathrm{~h})$ over 5 months of the year (May-Sep.). Meteorological data seems to be similar by measurement years. Therefore, meteorology has stopped taking new measurements for Adiyaman after 2010.

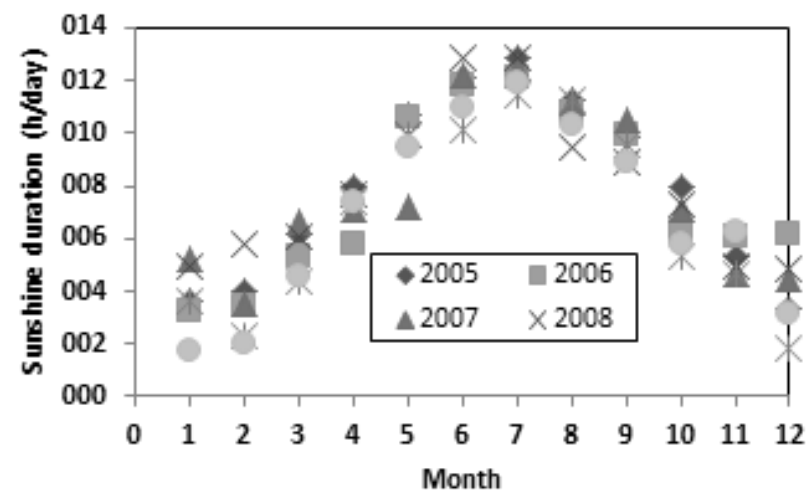

Fig. 4. Adiyaman sunshine duration from 2005 to 2010

\section{A Case Study}

Statistical analyzes were performed using solar radiation and sunshine duration data that was conducted from 2005 to 2010 in Adiyaman ( $38^{\circ}$ E46 $\left.17^{\prime} \mathrm{N}\right)$. Anström-Prescott equation is used to analyze the data. Daily extraterrestrial radiation on horizontal surface for Adiyaman is calculated using equation (1) [11].

$\mathrm{H}_{0}=\frac{24 \times 3600}{\pi} \mathrm{G}_{\mathrm{sc}} \cdot \mathrm{k}\left(\cos \emptyset \cos \delta \sin \omega_{\mathrm{s}}+\frac{\pi \omega_{\mathrm{s}}}{180} \sin \emptyset \sin \delta\right)$

Here, $\mathrm{G}_{\mathrm{sc}}$ solar coefficient $\left(1367 \mathrm{~W} / \mathrm{m}^{2}\right)$, $\mathrm{k}$ is eccentricity correction constant and calculated by equation (2) [11].

$k=1+0,033\left(\cos \frac{360 \mathrm{n}}{365}\right)$

Here, $\mathrm{n}$ is representing the number of days starting from the first day of January. $\delta$ is declination angle and calculated with Cooper equation (3) [11]: 
$\delta=23.45\left(360 \frac{284+n}{365}\right)$

$\omega_{s}$ is sunset hour angle and expressed equation (4) [11]:

$\omega_{s}=\cos ^{-1}(-\tan \emptyset \tan \delta)$

Regional day length $\left(S_{0}\right)$ is expressed with equation (5) [11] $S_{0}=\frac{2 \omega_{s}}{15}$

Statistical analyzes were performed by using linear, quadratic, cubic, logarithmic and exponential models. The models used in the analysis are given in Table 1 and comparison parameters used in the regression analysis are given in Table 2.

Table 1. The regression model used in data analysis

\begin{tabular}{|l|l|}
\hline Linear model & $\frac{H}{H_{0}}=a+b \frac{S}{S_{0}}$ \\
\hline Quadratic Model & $\frac{H}{H_{0}}=a+b \frac{S}{S_{0}}+c\left(\frac{S}{S_{0}}\right)^{2}$ \\
\hline Cubic Model & $\frac{H}{H_{0}}=a+b \frac{S}{S_{0}}+c\left(\frac{S}{S_{0}}\right)^{2}+d\left(\frac{S}{S_{0}}\right)^{3}$ \\
\hline Logarithmic model & $\frac{H}{H_{0}}=a+b \log \frac{S}{S_{0}}$ \\
\hline Exponential model & $\frac{H}{H_{0}}=a e^{b\left(\frac{S}{S_{0}}\right)}$ \\
\hline
\end{tabular}

Table 2. Comparison parameters used in the regression analysis

\begin{tabular}{|c|c|}
\hline$R_{1}{ }^{2}=1-\frac{\sum_{i=1}^{n}\left(\frac{H_{i, m}}{H_{i, o}}-\frac{H_{i, c}}{H_{i, o}}\right)^{2}\left(\frac{H_{i, m}}{H_{i, o}}-\left\langle\frac{\bar{H}_{m}}{H_{o}}\right\rangle\right)^{2}}{\sum^{2}}$ & $R_{2}{ }^{2}=1-\frac{\sum_{i=1}^{n}\left(H_{i, m}-H_{i, c}\right)^{2}}{\sum_{i=1}^{n}\left(H_{i, m}-\bar{H}_{m}\right)^{2}}$ \\
\hline$R M S E_{1}=\sqrt{\frac{1}{n}\left(\frac{H_{i, m}}{H_{i, o}}-\frac{H_{i, c}}{H_{i, o}}\right)^{2}}$ & $R M S E_{2}=\sqrt{\frac{1}{n}\left(H_{i, m}-H_{i, c}\right)^{2}}$ \\
\hline$M B E_{1}=\frac{1}{n} \sum_{i=1}^{n}\left(\frac{H_{i, m}}{H_{i, o}}-\frac{H_{i, c}}{H_{i, o}}\right)$ & $M B E_{2}=\frac{1}{n} \sum_{i=1}^{n}\left(H_{i, m}-H_{i, c}\right)$ \\
\hline$M A B E_{1}=\frac{1}{n} \sum_{i=1}^{n}\left(\mid \frac{H_{i, m}}{H_{i, o}}-\frac{H_{i, c}}{H_{i, o}}\right)$ & $M A B E_{2}=\frac{1}{n} \sum_{i=1}^{n}\left(\left|H_{i, m}-H_{i, c}\right|\right)$ \\
\hline$M P E_{1}=\frac{1}{n} \sum_{i=1}^{n}\left(\frac{H_{i, m}-H_{i, c}}{H_{i, m}}\right) 100$ & \\
\hline$\left.M A P E_{1}=\frac{1}{n} \sum_{i=1}^{n}\left(\mid \frac{H_{i, m}-H_{i, c}}{H_{i, m}}\right)\right) 100$ & $M P E_{2}=M P E_{1}$ \\
\hline
\end{tabular}

\section{Results and Discussion}

Solar energy systems applications always need solar data. These meteorological data are measured experimentally in several centers. But it is not possible to measure in everywhere. Instead, regression analysis is performed to create a model to estimate solar data for other region. Regression analysis is a statistical technique that is characterized by a mathematical model in order to estimate the variables in the relationship. Correlation coefficient is calculated to determine whether the reliability of the results obtained in this assay. In this study, experimental measurements were conducted for solar radiation in between 2005-2010 was analyzed statistically by using regression analysis for different models. Statistical analysis results are shown in Table 3. Table 3 reveals that the cubic model showed the best fit to the data for Adiyaman. However, quadratic, exponential and logarithmic model showed the best fit after the cubic model. There is a little difference between the cubic model with other models. This type of modeling with the assistance of the parameters estimated from data for certain region helps to predict solar values of other nearby regions. Solar maps covering the whole country is obtained as a result of modeling by using measurements in certain regions. The same method is applied to determine the country's wind the map. According to the wind measurements made at certain places, other parts of the region are estimated using various models and wind maps prepared.

Daily extraterrestrial radiation on horizontal surface for Adiyaman was calculated using equation (1). Solar radiation measurements data from 2005 to 2010 reaching on horizontal surface were taken from meteorology of Adiyaman. Taking the average of the data received, values of solar radiation reaching on the horizontal surface was found. Figure 5 shows the values of extraterrestrial and terrestrial solar radiation reaching on horizontal surface as monthly average for Adiyaman. As seen in Figure 5, the highest extraterrestrial solar radiation was calculated as $11.58 \mathrm{kWh} / \mathrm{m}^{2}$-day for June, and the lowest one was $4.16 \mathrm{kWh} / \mathrm{m}^{2}$-day in December. Considering measurements of solar radiation reaching on horizontal surface, the highest solar radiation with $7.00 \mathrm{kWh}$ $/ \mathrm{m}^{2}$-day was measured in June, the lowest one is 1.90 $\mathrm{kWh} / \mathrm{m}^{2}$-day in December. Cloudiness index is defined as the ratio of the monthly average solar radiation to extraterrestrial average solar radiation on the horizontal surface. According to the data given in Figure 5 cloudiness index took placed with the value of 0.42 in February, highest with 0.61 in July. Cloudiness index is quite important in solar energy applications. When calculating the solar energy incident on horizontal surface, index of cloudiness should be considered.

Day length for Adiyaman was calculated using equation (5). Sunshine duration was obtained by observations made by meteorology. Figure 6 shows the day length and sunshine duration for Adiyaman. As shown in Figure 6 maximum day length took placed in June with the value of $14.59 \mathrm{~h}$, and minimum took place in December with $9.40 \mathrm{~h}$. With respect to sunshine duration, maximum day length took placed in July with $12.28 \mathrm{~h}$, and minimum in February with $3.51 \mathrm{~h}$. Although the sunshine duration showed similar changes yearly but according to the cloudiness index seasonal variations may occur. For example, in February sunshine duration is the shortest while the day length is not. 


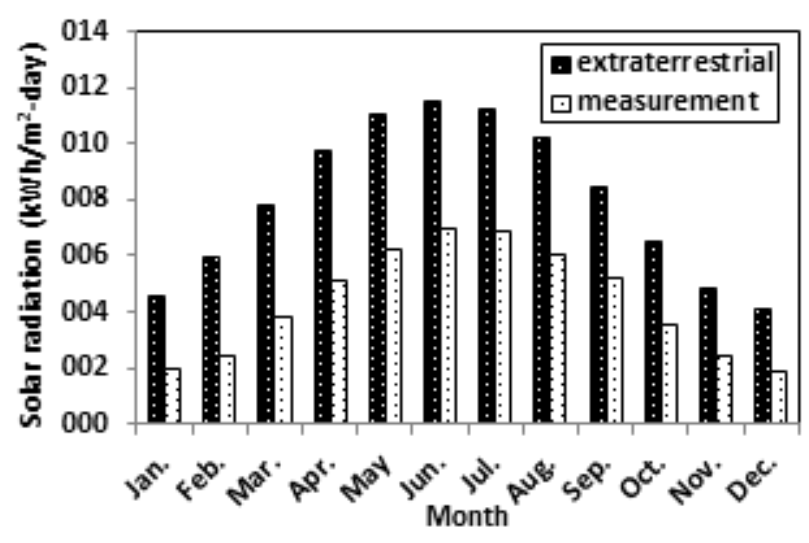

Fig. 5. Terrestrial and extraterrestrial radiation on horizontal surface for Adiyaman

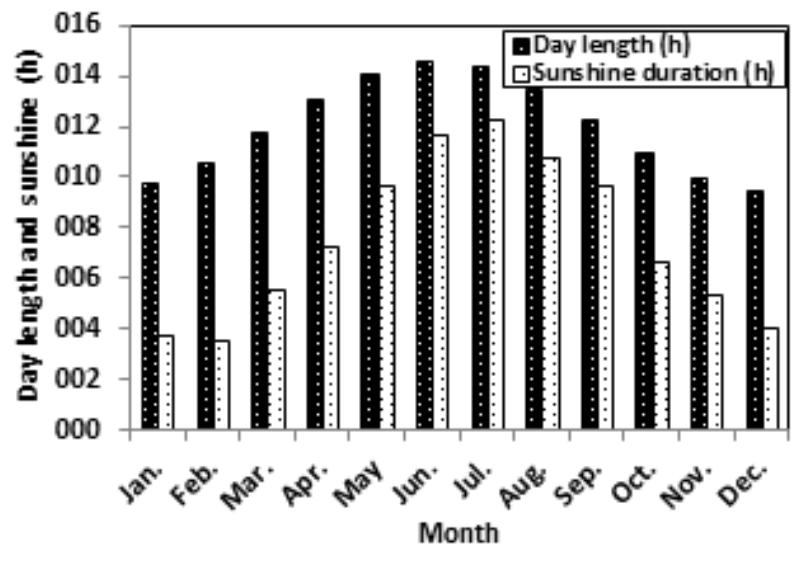

Fig. 6. Day length and sunshine duration for Adiyaman

Table 3. Regression results and statistical parameters for a variety of models for Adiyaman.

\begin{tabular}{lcccccccccc} 
& $R_{1}{ }^{2}$ & $R_{2}{ }^{2}$ & $\mathrm{RMSE}_{1}$ & $\mathrm{RMSE}_{2}$ & $\mathrm{MBE}_{1}$ & $\mathrm{MBE}_{2}$ & $\mathrm{MABE}_{1}$ & $\mathrm{MABE}_{2}$ & $\mathrm{MPE}_{1}$ & $\mathrm{MAPE}_{1}$ \\
\hline Linear & 0.772 & 0.972 & 0.0445 & 1.1641 & 0.0003 & 0.0318 & 0.0336 & 0.8941 & -1.06 & 7.24 \\
Quadratic & 0.789 & 0.976 & 0.0429 & 1.0772 & 0.0001 & 0.0454 & 0.0311 & 0.8087 & -0.95 & 6.73 \\
Cubic & 0.793 & 0.977 & 0.0424 & 1.0725 & 0.0004 & 0.0523 & 0.0309 & 0.8035 & -0.88 & 6.68 \\
Logarithmic & 0.746 & 0.974 & 0.0470 & 1.1234 & 0.0001 & 0.0926 & 0.0333 & 0.8465 & -1.00 & 7.42 \\
Exponential & 0.740 & 0.965 & 0.0475 & 1.3093 & 0.0032 & 0.0682 & 0.0371 & 1.0202 & -0.41 & 7.80 \\
\hline
\end{tabular}

\section{Conclusion}

Energy is the foremost of today's most important issues. Countries that produce their own energy are being more powerful economically but foreign energy-dependent countries are experiencing serious difficulties. Effects of global warming, which manifests itself in the last 50 years has led the country to renewable energy sources. In this study, statistical analysis was carried out using solar radiation data from 2005 to 2010 for Adiyaman. Linear, quadratic, cubic, logarithmic and exponential models are used in statistical analysis. In used models cubic model showed the best fit for these data. However, Quadratic, exponential, logarithmic, and linear models showed the best correlation after the cubic model respectively. Using this model, radiation values for other regions can be approximated. Thus, it is not necessary to measure the solar radiation in everywhere.

\section{Acknowledgement}

The authors are thankful to Turkish State Meteorological Service for wind speed data.

\section{Nomenclature}

$a-d \quad$ empirical constants

GsC solar constant $\left(\mathrm{G}_{\mathrm{sc}}=1367 \mathrm{~W} / \mathrm{m}^{2}\right)$

$H$ daily global solar radiation on horizontal surface $\left(\mathrm{MJ} / \mathrm{m}^{2}\right)$

Ho daily extraterrestrial radiation on horizontal surface $\left(\mathrm{MJ} / \mathrm{m}^{2}\right)$

$n \quad$ number of day of year starting from first of January

$k \quad$ eccentricity correction factor
$R^{2} \quad$ coefficient of determination

$S \quad$ sunshine duration (h)

So day length (h)

\section{Greek letters}

$\omega_{s} \quad$ sunset hour angle (degree)

$\delta \quad$ solar declination (degree)

$\varnothing \quad$ latitude of site (degree)

$\sigma \quad$ standard deviation

\section{Acronyms}

MAE mean absolute error

MABE mean absolute bias error

MAPE mean absolute percentage error

MBE mean bias error

MPE mean percentage error

NSE Nash-Sutcliffe equation

RMSE root mean square error

SEE standard error of estimate

\section{References}

[1] I. Dincer, M.A. Rosen, “Thermal energy storage: systems and applications", New York: John Wiley and Sons, 2003.

[2] M. Balat, "The use of renewable energy sources for energy in Turkey and potential trends", Energy Explor Exploit, 22: 241-57, 2004.

[3] J. Almorox, M. Bocco, "Enrique Willington, Estimation of daily global solar radiation from measured temperatures at Cañada de Luque, Córdoba, Argentina”, Renewable Energy 60: 382-387, 2013. 
[4] M. Yorukoglu, A.N. Celik, "A critical review on the estimation of daily global solar radiation from sunshine duration", Energy Conversion and Management 47: 2441-2450, 2006.

[5] I. Daut, M. Irwanto, Y.M. Irwan, N. Gomesh, N.S. Ahmad, "Combination of Hargreaves method and linear regression as a new method to estimate solar radiation in Perlis, Northern Malaysia”, Solar Energy 85: 2871-2880, 2011.

[6] J.I. Prieto, J.C. Martinez-Garcia, D. Garcia, "Correlation between global solar irradiation and air temperature in Asturias, Spain”, Solar Energy 83: 1076-1085, 2009.

[7] K. Papakostas, A. Bentoulis, V. Bakas, N. Kyriakis, "Estimation of ambient temperature bin data from monthly average temperatures and solar clearness index. Validation of the methodology in two Greek cities", Renewable Energy 32: 991-1005, 2007.

[8] J. Almorox, "Estimating global solar radiation from common meteorological data in Aranjuez, Spain", Turk J Phys 35: 53 - 64, 2011.

[9] General Directorate of Renewable Energy (EIE), "Solar map", Available at: $<$ http:// www.eie.gov.tr, 2015.

[10] Meteorology Regional Offices, , Turkish State Meteorological Service, Ankara, Turkey. Available at:<http:// www.mgm.gov.tr, 2015.

[11] J.A. Duffie, W.A. Beckman, "Solar Engineering of Thermal Processes", second ed. John Wiley \& Sons Inc., New York, 1991. 